\title{
hsa-miR-5580-3p inhibits oral cancer cell viability, proliferation and migration by suppressing LAMC2
}

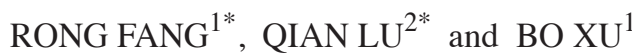 \\ ${ }^{1}$ Department of Gastroenterology, Puai Hospital, Tongji Medical College, \\ Huazhong University of Science and Technology, Wuhan, Hubei 430033; ${ }^{2}$ Department of Stomatology, \\ Wuhan Children's Hospital (Wuhan Maternal and Child Healthcare Hospital), Tongji Medical College, \\ Huazhong University of Science and Technology, Wuhan, Hubei 430015, P.R. China
}

Received February 28, 2020; Accepted March 16, 2021

DOI: $10.3892 / \mathrm{mmr} .2021 .12092$

\begin{abstract}
The present study aimed to explore whether and how microRNA-5580-3p (miR-5580-3p) affected oral cancer (OC) cell phenotypes via regulation of laminin subunit $\gamma 2$ (LAMC2). Bioinformatics analysis was used to identify miR-5580-3p/LAMC2, a novel interactome that, to the best of our knowledge, has not been studied previously in OC. In the present study, the expression levels of miR-5580-3p and LAMC2 were detected by reverse transcription-quantitative PCR, while the protein expression levels of LAMC2 were identified using western blotting. To determine the effects of miR-5580-3p and LAMC2 in OC, a number of experiments, including Cell Counting Kit-8, 5-bromo-2'-deoxyuridine cell proliferation and wound healing migration assays, were performed using OC SCC-4 and Cal-27 cell lines. Additionally, luciferase reporter assays were employed to examine the interaction between miR-5580-3p and LAMC2 mRNA. The results demonstrated that miR-5580-3p expression was downregulated, while LAMC2 expression was upregulated in $\mathrm{OC}$ tissues and cell lines. In addition to the observation that miR-5580-3p promoted the malignant phenotypes of OC, it was also revealed that miR-5580-3p inhibited OC cell viability, proliferation and migration by suppressing LAMC2. Therefore, the present study suggested that miR-5580-3p and
\end{abstract}

Correspondence to: Dr Bo Xu, Department of Gastroenterology, Puai Hospital, Tongji Medical College, Huazhong University of Science and Technology, 473 Hanzheng Street, Wuhan, Hubei 430033, P.R China

E-mail: xubo18707@163.com

${ }^{*}$ Contributed equally

Abbreviations: OC, oral cancer; LAMC2, laminin subunit $\gamma 2$; OSCC, oral squamous cell carcinoma; miRNA, microRNA; CCK-8, Cell Counting Kit-8; BrdU, 5-bromo-2'-deoxyuridine; NC, negative control

Key words: miRNA-5580-3p, LAMC2, oral cancer, migration, invasion
LAMC2 may be potential biomarkers and therapeutic targets for OC diagnosis and therapies in the future.

\section{Introduction}

Oral cancer $(\mathrm{OC})$ refers to a group of tumors found in the lining of the mouth, lips, throat, tongue or cheek (1). At present, $>540,000$ individuals are diagnosed with OC annually, and the 5-year survival rate of patients with OC is $<50 \%$ (1). Oral squamous cell carcinoma (OSCC) is the most common type of OC, ranking eighth in terms of cancer incidence worldwide (2). This type of mouth cancer has gradually become a public health problem due to its high incidence and low cure rate (3). Numerous methods, including surgery, radiotherapy and chemotherapy, have been used to treat OC; however, these treatments do not achieve the expected results (4-6). To enhance the prognosis of patients with OC, more treatment approaches should be explored.

Laminin subunit $\gamma 2$ (LAMC2) serves an important role in $\mathrm{OC}$, and the human LAMC2 gene is located on chromosome 1q25-q31 (7). More specifically, this gene has been reported to be involved in head and neck cancer (8). Laminin $\gamma 2$, which belongs to the laminin protein family, is a basal lamina glycoprotein encoded by the LAMC2 gene (9). As a specific biomarker, LAMC2 is expressed in several types of malignant cancer, including gastric cancer (10), esophageal squamous cell carcinoma (11) and pancreatic ductal adenocarcinoma (12). Furthermore, cell-surface receptors combine with LAMC2 to guide tumor migration and invasion, thus making it a possible effective cancer target $(7,11,13,14)$. To the best of our knowledge, the present study was the first to investigate the expression levels and effects of LAMC2 in OC.

With a length of 18-25 nucleotides, microRNAs (miRNAs/miRs) were previously regarded as junk RNAs that have no effects (15-17). However, previous studies revealed that when miRNAs are involved in the development of tumors, they can inhibit the translation of mRNAs and shorten the half-life of mRNAs (15-17). In tumors, most downregulated miRNAs function as tumor suppressors, whereas upregulated miRNAs function as cancer-promoting factors (18-21). Efficient diagnosis and prognosis of OC may become possible, with various tumors exhibiting a signature miRNA profile 
associated with tumor progression. Small non-coding RNA molecule miR-5580 was once identified along with another 84 miRNAs using the miRDeep 2 algorithm (22). The gene that encodes miR-5580 is located on chromosome14q22.2, according to the National Center for Biotechnology Information genome database (https://www.ncbi.nlm.nih. gov/gene/100847076). However, to the best of our knowledge, no previous study has explored the effects of miR-5580-3p in human cancer types.

Therefore, the roles of miR-5580-3p and LAMC2 in OC deserve further investigation. The purpose of the present study was to investigate whether and how miR-5580-3p affected OC cell phenotypes by regulating LAMC2.

\section{Materials and methods}

Bioinformatics analysis. Gene Expression Omnibus (GEO, https://www.ncbi.nlm.nih.gov/geo), a public functional database, stores mRNA and non-coding RNA expression profiles. Three mRNA expression profiles, GSE19089 (23), GSE23558 (24) and GSE138206 (https://www.ncbi.nlm.nih. gov/geo/query/acc.cgi?acc $=$ GSE138206), which included the mRNA expression profiling in OC were analyzed using the GEO2R built-in algorithm by $\mathrm{R}$ software 4.0.4 (https://www.r-project.org/) on the GEO database with the criteria of $\log \mathrm{FC} \geq 1.5$ and adjusted $\mathrm{P}<0.05$. The intersected genes from the three mRNA expression profiles were uploaded to the Search Tool for the Retrieval of Interacting Genes/Proteins database (https://string-db.org/) for enrichment analysis. The Gene Expression Profiling Interactive Analysis (GEPIA) survival analysis tool (http://gepia2.cancer-pku.cn/\#survival) was used to study the prognostic effects of the genes of interest in human head and neck squamous cell carcinoma (HNSCC), and to obtain the expression of LAMC2 in HNSCC. The target miRNAs of LAMC2 predicted by TargetScan Human 7.2 (25) were eventually overlapped with the downregulated miRNAs in the GSE98463 dataset (a miRNA microarray dataset) (26) with $\log \mathrm{FC}<-1.5$ and $\mathrm{P}<0.05$.

Clinical samples collection from patients with $O C$. A total of 40 patients diagnosed with OC at Puai Hospital, Tongji Medical College of Huazhong University of Science and Technology (Wuhan, China) participated in the present study. The inclusion criteria were patients with $\mathrm{OC}$ without radiotherapy, chemotherapy or other treatments, and the exclusion criteria were the patients with $\mathrm{OC}$ and with other diseases. The participants were divided into a training set $(\mathrm{n}=20)$ and a validation set $(n=20$; the requirement of Mann-Whitney test). The cancer tissues and corresponding adjacent healthy tissues ( $<3 \mathrm{~cm}$ from tumor tissues) were collected between January 2020 and March 2020, frozen and embedded in paraffin until they were used in the present study. The clinical characteristics of the 40 patients are listed in Table I. The present study was approved by the Ethics Committee of Puai Hospital, Tongji Medical College, Huazhong University of Science and Technology (approval no. KY2020-501-01). All patients who participated in the present study provided written informed consent. It was ensured that all experimental procedures, including the use and collection of tissues, followed the ethical standards set out in the Declaration of Helsinki.
$R N A$ extraction and reverse transcription-quantitative $P C R$ (RT-qPCR). TRIzol reagent (Invitrogen; Thermo Fisher Scientific, Inc.) was used to extract total RNA from tissues and cells, according to the manufacturer's protocols. miRNAs were purified using the miRcute miRNA isolation kit (cat. no. DP501; Tiangen Biotech Co., Ltd.). Prior to the RNA reverse transcription process, RNA was quantified using gel electrophoresis. miR-5580-3p reverse transcription (cat. no. KR211; Tiangen Biotech Co., Ltd.) and LAMC2 mRNA reverse transcription (cat. no. RR037A; Takara Bio, Inc.) were then performed, according to the manufacturer's protocols. Subsequently, the 7500 Fast Dx Real-Time PCR Instrument (Applied Biosystems; Thermo Fisher Scientific, Inc.) was used to analyze the expression levels of miR-5580-3p using a miRcute Plus miRNA qPCR kit (SYBR Green) (cat. no. FP411; Tiangen Biotech Co., Ltd.) with the thermocycling conditions: $95^{\circ} \mathrm{C} 15 \mathrm{~min}, 40$ cycles of $94^{\circ} \mathrm{C} 20 \mathrm{sec}$ and $60^{\circ} \mathrm{C} 34 \mathrm{sec}$, and the mRNA expression levels of LAMC2 were analyzed using a TB Green ${ }^{\circledR}$ Premix Ex Taq ${ }^{\mathrm{TM}}$ kit (cat. no. RR420A; Takara Bio, Inc.) with the thermocycling conditions: $95^{\circ} \mathrm{C} 30 \mathrm{sec}$, 40 cycles of $95^{\circ} \mathrm{C} 5 \mathrm{sec}$ and $60^{\circ} \mathrm{C} 30 \mathrm{sec}$. U6 and GAPDH were used as reference genes for miR-5580-3p and LAMC2 mRNA quantification using $2^{-\Delta \Delta C q}$ method (27), respectively. All primers are listed in Table II.

Cell lines and transfection. The human OC cell lines (SCC-4, SCC-9 and Cal-27), as well as the human oral epithelial cell line (HOEC; cat. no. BNCC340217), were purchased from BeNa Culture Collection; Beijing Beina Chuanglian Biotechnology Research Institute. SCC-4, SCC-9, Cal-27 and HOEC cells were cultured in DMEM (cat. no. C11965500BT; Gibco; Thermo Fisher Scientific, Inc.) supplemented with 10\% FBS (cat. no. 10439024; Gibco; Thermo Fisher Scientific, Inc.). These cells were subsequently placed in a humidified incubator at $37^{\circ} \mathrm{C}$ with $5 \% \mathrm{CO}_{2}$. All plasmids, including small interfering (si)RNA-LAMC2 (cat. no. siG000003918A-1-5), overexpression (OE)-LAMC2, miR-5580-3p mimic (cat. no. miR10022274-1-5), miR-5580-3p inhibitor and negative controls (NC), such as si-NC and OE-NC, were obtained from Guangzhou RiboBio Co., Ltd. SCC-4 and Cal-27 cells were seeded $\left(1 \times 10^{6}\right.$ cells/well) into plates for $24 \mathrm{~h}$. Subsequently, the samples were transfected with $50 \mathrm{nM}$ plasmids using Lipofectamine ${ }^{\circledR} 2000$ reagent (cat. no. 11668027; Thermo Fisher Scientific, Inc.) for $48 \mathrm{~h}$ at $37^{\circ} \mathrm{C}$. The following sequences were used in the present study: miR-5580-3p mimic, 5'-UGC UGGCUCAUUUCAUAUGUGUGCUGAGAAAAUUCACA CAUAUGAAGUGAGCCAGCAC-3'; miR-5580-3p inhibitor, 5'-ACGACCGAGUAAAGUAUACACACGACUCUUUUA AGUGUGUAUACUUCACUCGGUCG-3'; miR-5580-3p mimic NC, 5'-UCACAACCUCCUAGAAAGAGUAGA-3'; and inhibitor NC, 5'-CAGTACTTTTGTGTAGTACAA-3'. The $\mathrm{NC}$ for LAMC2 overexpression was an empty pEXP-RB-Mam vector (Guangzhou RiboBio Co., Ltd.), and the NC for LAMC2 knockdown was an empty pRNAT-U6.1 vector (Guangzhou RiboBio Co., Ltd.). After $48 \mathrm{~h}$ transfection, the transfected cells were used for the subsequent experiments.

Luciferase reporter assay. SCC-4 and Cal-27 cells were seeded into 96 -well plates at a density of $3 \times 10^{5}$ cells/well. The wild-type (Wt) pEZX-MT05-LAMC2-3' 
Table I. Clinical characteristics of patients with oral cancer in the training $(n=20)$ and validation $(n=20)$ sets.

\begin{tabular}{|c|c|c|}
\hline $\begin{array}{l}\text { Pathological } \\
\text { characteristics }\end{array}$ & $\begin{array}{c}\text { Training set, } \\
\mathrm{n}(\%)\end{array}$ & $\begin{array}{c}\text { Validation set, } \\
\mathrm{n}(\%)\end{array}$ \\
\hline \multicolumn{3}{|l|}{ Age, years } \\
\hline$>50$ & $12(60)$ & $10(50)$ \\
\hline$\leq 50$ & $8(40)$ & $10(50)$ \\
\hline \multicolumn{3}{|l|}{ Sex } \\
\hline Male & $11(55)$ & $12(60)$ \\
\hline Female & $9(45)$ & $8(40)$ \\
\hline \multicolumn{3}{|l|}{ Site } \\
\hline Buccal mucosa & $6(30)$ & $5(25)$ \\
\hline Tongue & $6(30)$ & $6(30)$ \\
\hline Alveolus & $8(40)$ & $9(45)$ \\
\hline \multicolumn{3}{|l|}{ T classification } \\
\hline $\mathrm{T} 1-\mathrm{T} 2$ & $11(55)$ & $10(50)$ \\
\hline $\mathrm{T} 3$ & $6(30)$ & $6(30)$ \\
\hline $\mathrm{T} 4$ & $3(15)$ & $4(20)$ \\
\hline \multicolumn{3}{|l|}{$\mathrm{N}$ classification } \\
\hline N0 & $9(45)$ & $8(40)$ \\
\hline N1 & $7(35)$ & $8(40)$ \\
\hline $\mathrm{N} 2$ & $4(20)$ & $4(20)$ \\
\hline \multicolumn{3}{|l|}{ Metastasis } \\
\hline No & $20(100)$ & $20(100)$ \\
\hline Yes & 0 & 0 \\
\hline \multicolumn{3}{|c|}{ Histological differentiation } \\
\hline Well & $6(30)$ & $8(40)$ \\
\hline Moderate & $9(45)$ & $7(35)$ \\
\hline Poor & $5(25)$ & $5(25)$ \\
\hline
\end{tabular}

T, tumor; $\mathrm{N}$, node.

untranslated region (3'UTR) constructs and the mutant-type (Mut) pEZX-MT05-LAMC-3'UTR constructs were purchased from GeneCopoeia, Inc. The 3'UTR constructs were co-transfected with miR-5580-3p mimic, miR-5580-3p inhibitor, mimic control or inhibitor control into SCC-4 and Cal-27 cells using Lipofectamine 2000 reagent. Subsequently, the Secrete-Pair Dual Luminescence assay kit (cat. no. LF031; GeneCopoeia, Inc.) was used to detect the firefly and secreted alkaline phosphatase (SEAP) activities. Cells were collected after $72 \mathrm{~h}$ of transfection and the fluorescence intensity was measured. Relative luciferase activity was normalized to SEAP.

Cell Counting Kit-8 (CCK-8) assay. Cell viability was determined using a CCK-8 assay (cat. no. HY-K0301; MedChemExpress). Briefly, 1,500 transfected SCC-4 and Cal-27 cells were seeded into the wells of 96-well plates and cultured at $37^{\circ} \mathrm{C}$ with $5 \% \mathrm{CO}_{2}$ for $24 \mathrm{~h}$. From the next day, at 0 , 24, 48 and $72 \mathrm{~h}, 10 \mu \mathrm{l} \mathrm{CCK}-8$ solution was added to the corresponding wells of each group. Next, the plate was incubated for $4 \mathrm{~h}$. Finally, the optical density (OD) at $450 \mathrm{~nm}$ of each well was determined using a microplate reader.
Table II. Primer sequences included in the present study.

\begin{tabular}{ll}
\hline Genes & \multicolumn{1}{c}{ Primer sequences $\left(5^{\prime} \rightarrow 3^{\prime}\right)$} \\
\hline miR-5580-3p & F: CACAGTTGAAGAGAGCCAGCAC \\
& R: CAGTGCGTGTCGTGGAGT \\
LAMC2 & F: GGAGCTGGAGTTTGACACGA \\
& R: GAGCATGGAGCTGGAAGGTT \\
GAPDH & F: ATGGAGAAGGCTGGGGCTC \\
U6 & R: AAGTTGTCATGGATGACCTTG \\
& F: TGCGGGTGCTCGCTTCGGCAGC \\
& R: CCAGTGCAGGGTCCGAGGT
\end{tabular}

F, forward; R, reverse; miR-5580-3p, microRNA-5580-3p; LAMC2, laminin subunit $\gamma 2$.

\begin{abstract}
5-Bromo-2'-deoxyuridine (BrdU) cell proliferation assay. A BrdU incorporation assay was used to evaluate cell proliferation. After the transfected SCC- 4 and Cal-27 cells ( $3 \times 10^{5}$ cells/well) were seeded into 96-well plates for 1 day, the old medium was replaced with DMEM without FBS. Subsequently, $10 \mu 1$ BrdU (cat. no. ab126556; Abcam) was added to each well for an incubation period of $4 \mathrm{~h}$ to allow proliferating cells to incorporate BrdU into their DNA. Then, the cells were fixed using the fixing solution included in the kit. Primary antibody against BrdU (prediluted, ready-to-use, provided in the kit) and secondary HRP-conjugated antibody $(1: 2,000$, provided in the kit) were sequentially added to the wells and incubated at room temperature. 3,3',5,5'-tetramethylbenzidine solution was added to develop the color. Finally, the OD at $450 \mathrm{~nm}$ was measured using a scanning multi-well spectrophotometer immediately after the stop solution was added.
\end{abstract}

Wound healing migration assay. A wound healing assay was performed to examine cell migration. Briefly, SCC-4 and Cal-27 cells $\left(3 \times 10^{6}\right.$ cells/well) were seeded into 12 -well plates for $24 \mathrm{~h}$. Once the cell density reached $80 \%$, the fused cell monolayer was scratched in the center using a $20-\mu 1$ micropipette tip. Subsequently, the non-adherent cells were washed off with PBS. The DMEM medium was then replaced with serum-free DMEM medium, and the cells were cultured for another $24 \mathrm{~h}$. At 0 and $24 \mathrm{~h}$, images were captured under a light microscope at 100x magnification to observe the wound width. The migration rate was calculated as: (wound width at $0 \mathrm{~h}$-wound width at $24 \mathrm{~h}$ )/wound width at $0 \mathrm{~h}$.

Western blotting. RIPA buffer (cat. no. 20-188; Sigma-Aldrich; Merck KGaA) with 5 mM EDTA (cat. no. V900106; Sigma-Aldrich; Merck KGaA) and PMSF (cat. no. 78830; Sigma-Aldrich; Merck KGaA) was used to extract and lyse protein from SCC-4 and Cal-27 cells. After determining protein concentration by BCA Protein Assay Kit (Thermo Fisher Scientific, Inc.), $30 \mu \mathrm{g}$ protein was separated via SDS-PAGE on $10 \%$ gel. The separated proteins were then transferred to PVDF membranes (cat. no. ISEQ00010; EMD Millipore). Next, the membranes were blocked with $5 \%$ milk in TBS with $0.1 \%$ Tween-20 at room temperature for $2 \mathrm{~h}$. Subsequently, the membranes were incubated with primary 
antibodies against LAMC2 (1:1,000; cat. no. ab210959; Abcam) and GAPDH (1:5,000; cat. no. ab181602; Abcam) at $4^{\circ} \mathrm{C}$ overnight. The following day, the membranes were incubated with the Goat Anti-Rabbit IgG H\&L (HRP) antibody (1:10,000; cat. no. ab97051; Abcam) for $2 \mathrm{~h}$ at room temperature. Finally, ECL reagent (cat. no. 1705062; Bio-Rad Laboratories, Inc.) was used to visualize the protein signals. Image Lab v3.0 software (Bio-Rad Laboratories, Inc.) was used for densitometry.

Statistical analysis. The experiments were repeated three times, and the data were shown as mean \pm standard deviation. SPSS v23.0 (IBM Corp.) was used to analyze all data collected in the present study. The Wilcoxon test was used to analyze the differences between tumor and healthy groups for tissue data. Unpaired Student's t-test was used to analyze the differences between two groups for cell experiments. One-way ANOVA with Dunnett's post hoc test was used to evaluate the differences among multiple groups in cell experiments. $\mathrm{P}<0.05$ was considered to indicate a statistically significant difference.

\section{Results}

miR-5580-3p/LAMC2 as a potential biomarker and therapeutic target in $O C$. By analyzing three mRNA expression profiles (GSE19089, GSE23558 and GSE138206), 35 common differentially expressed genes were obtained using the criteria of $\log \mathrm{FC} \geq 1.5$ and adjusted $\mathrm{P}<0.05$ (Fig. $1 \mathrm{~A}$ and $\mathrm{B}$ ). The mRNA expression analysis results for the GSE19089, GSE23558 and GSE138206 datasets are shown in Tables SI-III. The 35 genes were uploaded to the Search Tool for the Retrieval of Interacting Genes/Proteins database for enrichment analysis. The results revealed that the 'extracellular matrix organization' biological process and the 'extracellular matrix component' were significantly enriched terms, in which LAMC2, collagen type IV $\alpha 6$ chain and laminin subunit $\alpha 3$ were involved (Fig. 1C). Subsequently, the GEPIA survival analysis tool (http://gepia. cancer-pku.cn/detail.php) was used to study the prognostic effects of the three genes in human HNSCC. The results revealed that LAMC2 was a prognostic marker (Fig. 1D). By analyzing GEPIA expression data, it was also identified that LAMC2 expression was markedly upregulated in HNSCC (Fig. 1E). Therefore, LAMC2 was considered to be the gene of interest. The target miRNAs of LAMC2 predicted by TargetScan Human 7.2 (25) were overlapped with the downregulated miRNAs in the GSE98463 dataset (a miRNA microarray dataset) (26) with $\log \mathrm{FC}<-1.5$ and $\mathrm{P}<0.05$. The results indicated that miR-5580-3p was a potential cancer suppressor in OC (Fig. 1F). The targets of LAMC2 predicted by TargetScan Human 7.2 are listed in Table SIV. The analysis results for the GSE98463 dataset are shown in Table SV.

Upregulation of LAMC2 in OC. Compared with that in adjacent healthy tissues, LAMC2 mRNA expression was upregulated $\sim 2$-fold in cancerous tissues in the training and validation sets (Fig. 2A and B). LAMC2 mRNA and protein expression levels were significantly upregulated in cancer cell lines, particularly in Cal-27 and SCC-4 cells, compared with in the HOEC cell line (Fig. 2C and D). Therefore, SCC-4 and Cal-27 cells were selected for the follow-up experiments.
LAMC2 enhances the viability, proliferation and migration of OC cells. The successful transfection of si-LAMC2, si-NC, OE-LAMC2 and OE-NC into SCC-4 and Cal-27 cells was demonstrated. LAMC2 mRNA expression in the OE-LAMC2 group was increased 3-fold compared with that in the OE-NC group. Furthermore, LAMC2 mRNA expression was decreased by 0.7 -fold in the si-LAMC2 group compared with that in the si-NC group (Fig. 3A). Additionally, it was observed that the cell viability in the OE-LAMC2 group was 0.5 -fold higher compared with that in the OE-NC group; however, that in the si-LAMC2 group was $\sim 0.3$-fold lower compared with that in the si-NC group in SCC-4 and Cal-27 cells at $72 \mathrm{~h}$ (Fig. 3B). Cells in the OE-LAMC2 group exhibited a 0.3 -fold increase in cell proliferation compared with cells in the OE-NC group. Nevertheless, cells in the si-LAMC2 group had a 0.3 -fold decline in the cell proliferation level compared with cells in the si-NC group (Fig. 3C). Furthermore, it was observed that LAMC2 overexpression accelerated the wound healing process by 0.3 -fold, whereas LAMC 2 knockdown decreased it by $\sim 0.3$-fold. This observation suggested that LAMC2 overexpression enhanced OC cell migration (Fig. 3D). Overall, LAMC2 improved the viability, proliferation and migration of OC cells.

LAMC2 is a downstream target gene of miR-5580-3p. The complementary relationship between miR-5580-3p and LAMC2 mRNA is shown in Fig. 4A. Luciferase activity in the cells co-transfected with Wt LAMC2 mRNA 3'UTR and miR-5580-3p mimic was decreased by 0.5 -fold compared with that in the cells co-transfected with Wt LAMC2 mRNA 3'UTR and miR-5580-3p mimic-NC plasmids in both cell lines. On the other hand, the luciferase activity in cells co-transfected with Wt LAMC2 mRNA 3'UTR and miR-5580-3p inhibitor was markedly increased by $\sim 2$-fold compared with that in the cells co-transfected with Wt LAMC2 mRNA 3'UTR and miR-5580-3p inhibitor-NC (Fig. 4B). The expression levels of miR-5580-3p were 0.5 -fold lower in OC tissues compared with in the healthy tissues in both the training and validation sets (Fig. 4C and D). The results of RT-qPCR revealed that miR-5580-3p expression was significantly downregulated in OC cell lines, particularly in Cal-27 and SCC-4 cells, compared with in the HOEC cell line (Fig. 4E). miR-5580-3p was significantly upregulated in the mimic group, whereas LAMC2 mRNA was significantly downregulated in the mimic group (Fig. S1). In addition, miR-5580-3p expression was markedly increased ( 2-fold) in the mimic + OE-NC and mimic + OE-LAMC2 groups, compared with in the mimic-NC + OE-NC group in Cal-27 and SCC- 4 cells. LAMC2 expression was decreased by $\sim 0.8$-fold in the mimic + OE-NC group, but increased $\sim 4$-fold in the mimic-NC + OE group compared with in the mimic-NC + OE-NC group in Cal-27 and SCC-4 cells (Fig. 4F). These results demonstrated that miR-5580-3p directly targeted LAMC2.

miR-5580-3p inhibits OC cell viability, proliferation and migration by suppressing LAMC2. To further investigate whether miR-5580-3p inhibited the viability, proliferation and migration of OC cells by regulating LAMC2 mRNA, rescue experiments were designed. The results of the CCK-8 assay 
A

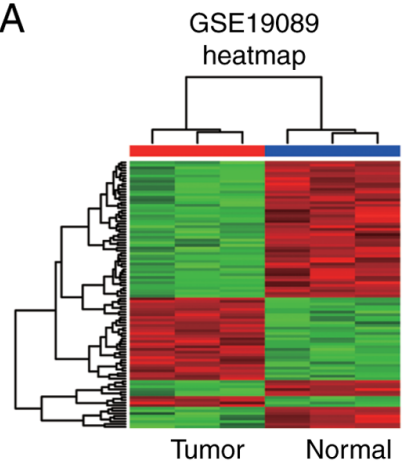

B

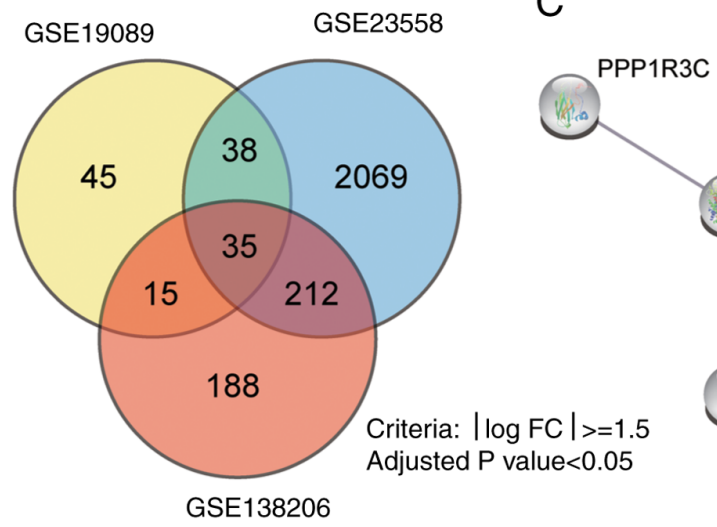

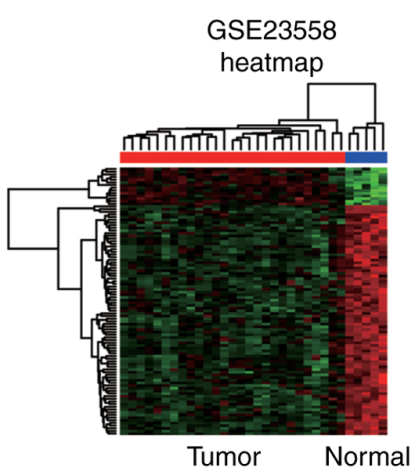

C

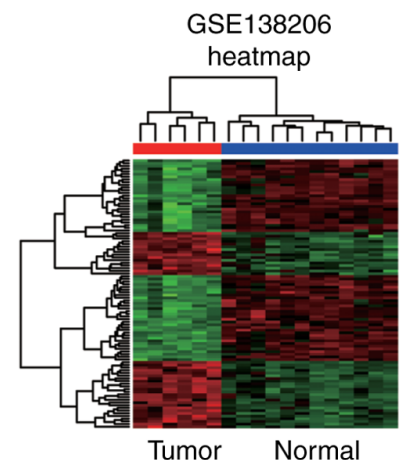

Tumor Normal

D
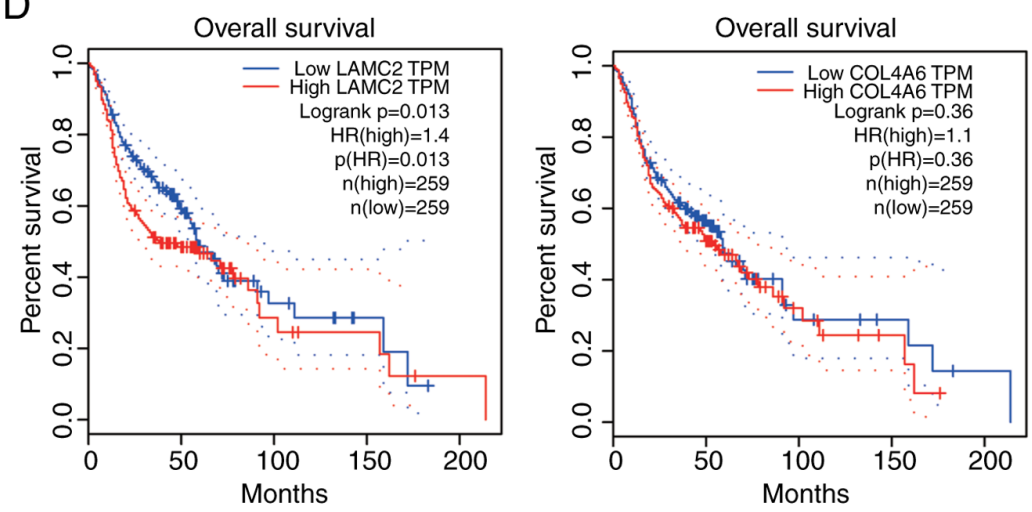

PGAM2

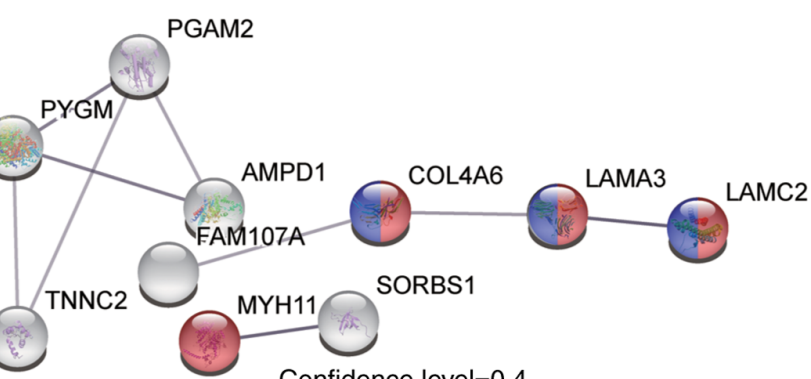

Confidence level=0.4

GO:0030198: extracellular matrix organization GO:0044420: extracellular matrix component

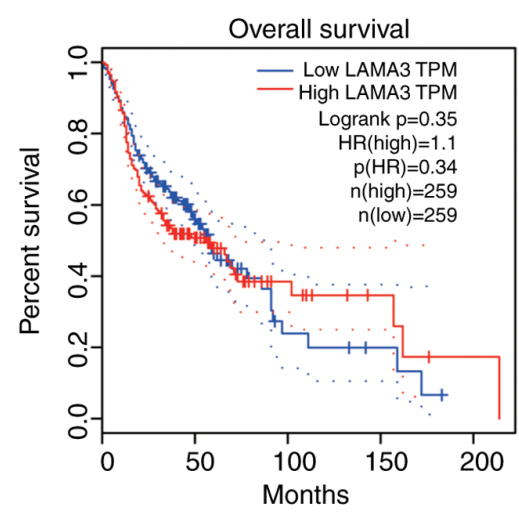

E

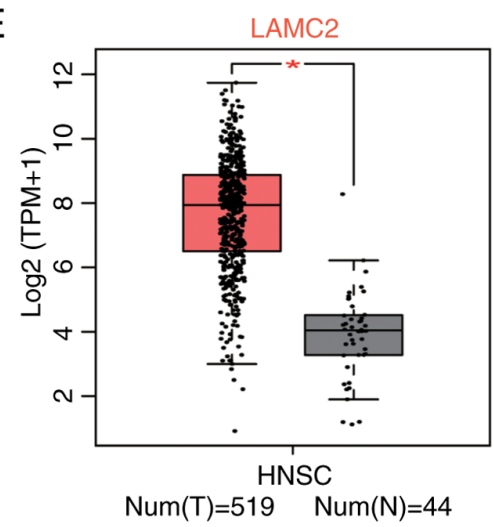

F Target miRNAs of LAMC2 TargetScan human 7.2

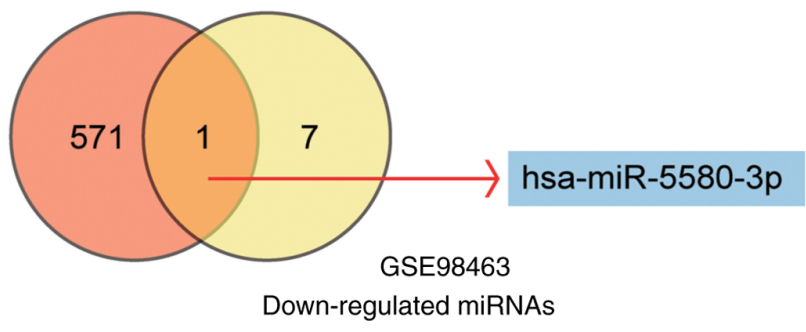

Criteria: $\log \mathrm{FC}<=-1.5$

$P$ value $<0.05$

Figure 1. Identification of miR-5580-3p and LAMC2 as potential biomarkers and therapeutic targets in OC. (A) Heatmaps of DEGs in three OC Gene Expression Omnibus datasets (GSE19089, GSE23558 and GSE138206) using R software 4.0.4. (B) Venn diagram revealing that 35 common DEGs were identified using the criteria of $\log \mathrm{FC} \geq 1.5$ and adjusted $\mathrm{P}<0.05$. (C) The $35 \mathrm{DEGs}$ were analyzed using the Search Tool for the Retrieval of Interacting Genes/Proteins database, and the extracellular matrix organization biological process and extracellular matrix component were identified as enriched terms. Genes that were involved in the two included LAMC2, COL4A6 and LAMA3. (D) GEPIA survival analysis was employed to study the prognostic effects of the three genes in HNSCC. (E) By interrogating GEPIA expression data, it was also revealed that LAMC2 expression was upregulated in HNSCC. "P<0.01. (F) Intersection of the target miRNAs of LAMC2 identified using TargetScan Human 7.2 and the downregulated miRNAs in the GSE98463 dataset (criteria, $\operatorname{logFC}<-1.5$ and adjusted $\mathrm{P}<0.05$ ). COL4A6, collagen type IV $\alpha 6$ chain; DEGs, differentially expressed genes; FC, fold-change; GEPIA, Gene Expression Profiling Interactive Analysis; HNSCC, head and neck squamous cell carcinoma; LAMA3, laminin subunit $\alpha 3$; LAMC2, laminin subunit $\gamma 2$; miR-5580-3p, microRNA-5580-3p; miRNAs, microRNAs; num $(\mathrm{T})$, number of the tumor group; $\mathrm{n}(\mathrm{N})$, number of the normal group; $\mathrm{OC}$, oral cancer. 


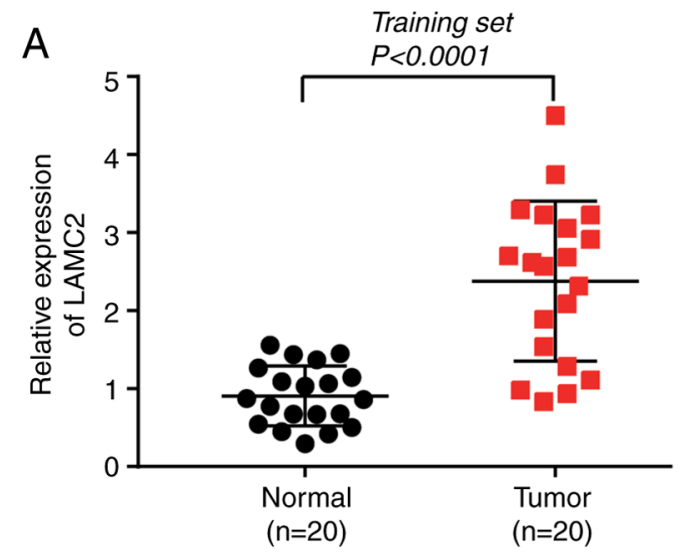

C

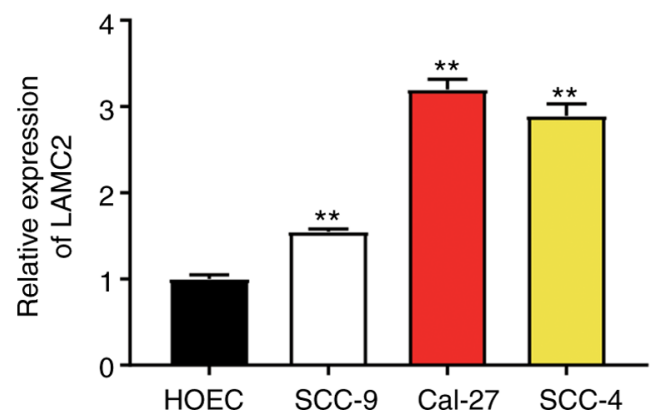

B
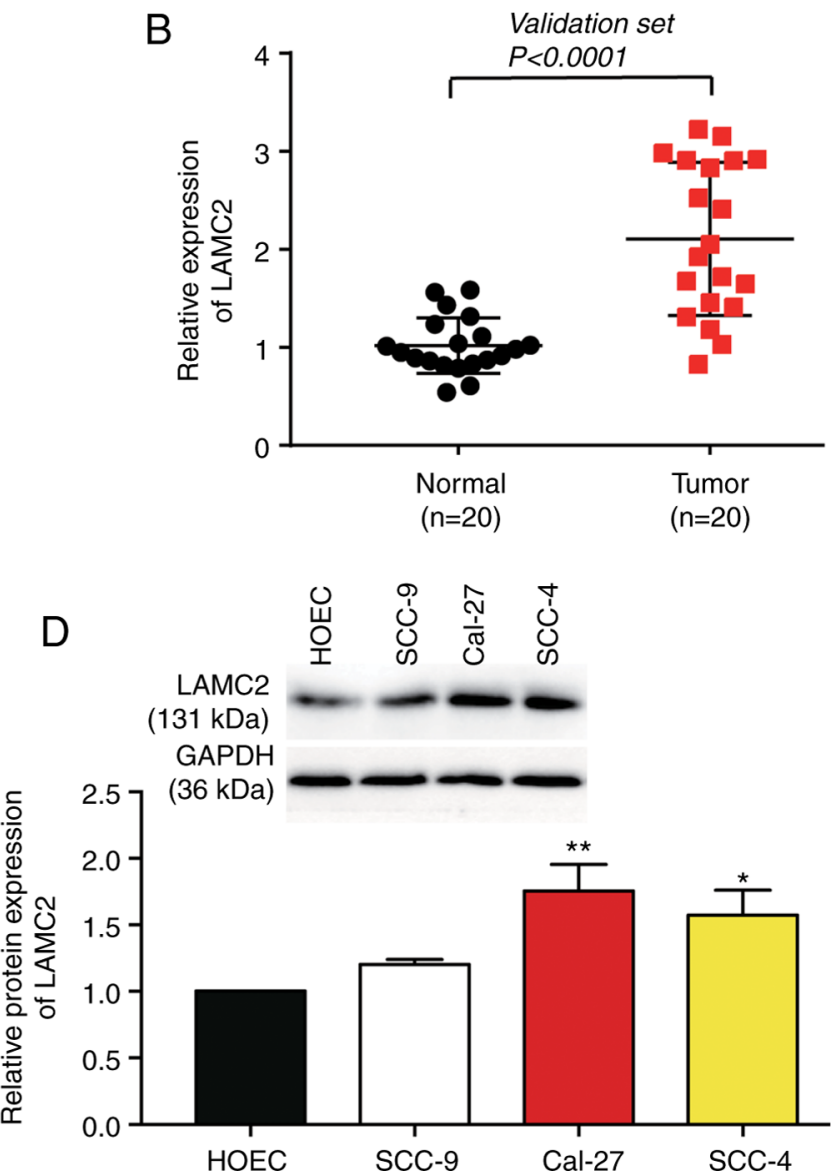

Figure 2. LAMC2 expression in oral cancer. (A) mRNA expression levels of LAMC2 were higher in oral tumor tissues than in adjacent healthy tissues in the training set according to RT-qPCR analysis. P $<0.001$ (Mann-Whitney test). (B) mRNA expression levels of LAMC2 were higher in oral tumor tissues compared with those in adjacent healthy tissues in the validation set according to RT-qPCR analysis. P<0.001 (Mann-Whitney test). (C) mRNA expression levels of LAMC2 were higher in oral tumor cell lines than in the normal oral HOEC cell line according to RT-qPCR analysis. ${ }^{* *} \mathrm{P}<0.01 \mathrm{vs}$. HOEC cell line. (D) Protein expression levels of LAMC2 were increased in oral tumor cell lines compared with in the HOEC cell line according to western blotting. ${ }^{*} \mathrm{P}<0.05$ and ${ }^{* *} \mathrm{P}<0.01$ vs. HOEC cell line. LAMC2, laminin subunit $\gamma 2$; RT-qPCR, reverse transcription-quantitative PCR; HOEC, human oral epithelial cell line.

revealed that the cell viability at $72 \mathrm{~h}$ was decreased in the miR-5580-3p mimic + OE-NC group, whereas the cell viability in the mimic-NC+OE-LAMC2 group was increased, compared with that in the mimic-NC+OE-NC group. The viability of cells in the miR-5580-3p mimic + OE-LAMC2 group was similar to that of cells in the mimic-NC + OE-NC group, suggesting that LAMC2 could reverse the effect of miR-5580-3p on OC cell viability (Fig. 5A). Furthermore, cell proliferation was decreased by $\sim 0.2$-fold in the miR-5580-3p mimic + OE-NC group, while that in the mimic-NC + OE-LAMC2 group was increased by nearly 0.5 -fold compared with that in the mimic-NC + OE-NC group. In addition, in the miR-5580-3p mimic + OE-LAMC2 group, the effect of miR-5580-3p on OC cell proliferation was reversed (Fig. 5B). Furthermore, it was observed that the migration rate was decreased by 0.2 -fold in the miR-5580-3p mimic + OE-NC group, while that in the mimic-NC + OE-LAMC2 group was increased by 0.3 -fold compared with that in the mimic-NC + OE-NC group. Additionally, in the miR-5580-3p mimic + OE-LAMC2 group, the effect of miR-5580-3p on OC cell migration was reversed (Fig. 5C). Overall, the results demonstrated that miR-5580-3p inhibited OC cell viability, proliferation and migration by suppressing LAMC2.

\section{Discussion}

The present experiments demonstrated that LAMC2 expression was upregulated in OC tissues and cell lines, whereas miR-5580-3p expression was downregulated in OC tissues and cells. Following overexpression of LAMC2, cell viability, proliferation and migration were increased notably in SCC-4 and Cal-27 cells. Whereas upregulation of miR-5580-3p led to the opposite results. Following co-transfection of miR-5580-3p mimic in LAMC2-overexpressing cell lines, the effects on cell viability, proliferation and migration abilities were reversed.

Increasing reports have revealed that LAMC2 expression is upregulated in various types of cancer, including gastric carcinoma, lung carcinoma, colorectal carcinoma, pancreas carcinoma, cervix carcinoma, oral carcinoma and melanoma (7,28-34). These previous studies demonstrated that LAMC2 enhanced tumor aggressiveness and was associated with shorter survival time, and high recurrence or metastasis rate in patients (7,28-34). Additionally, in a study by Lindberg et al (35), which included 20 LAMC2-positive tumors, in 11 grade one cases of incipient carcinoma, LAMC2 had a similar expression pattern to plasminogen activator inhibitor-1 (PAI-1). These results suggested that PAI-1 and 

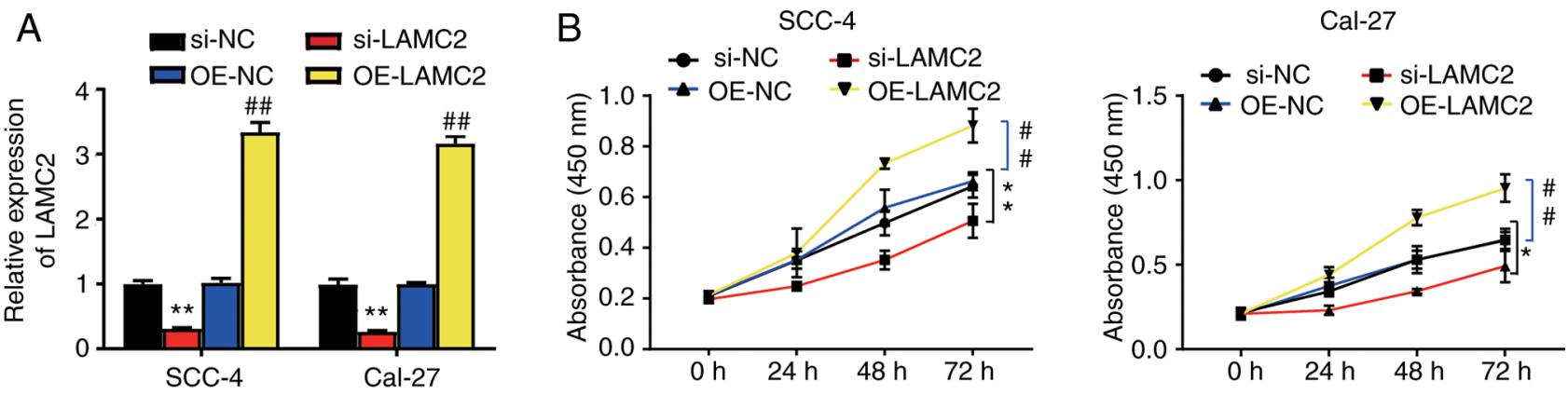

C
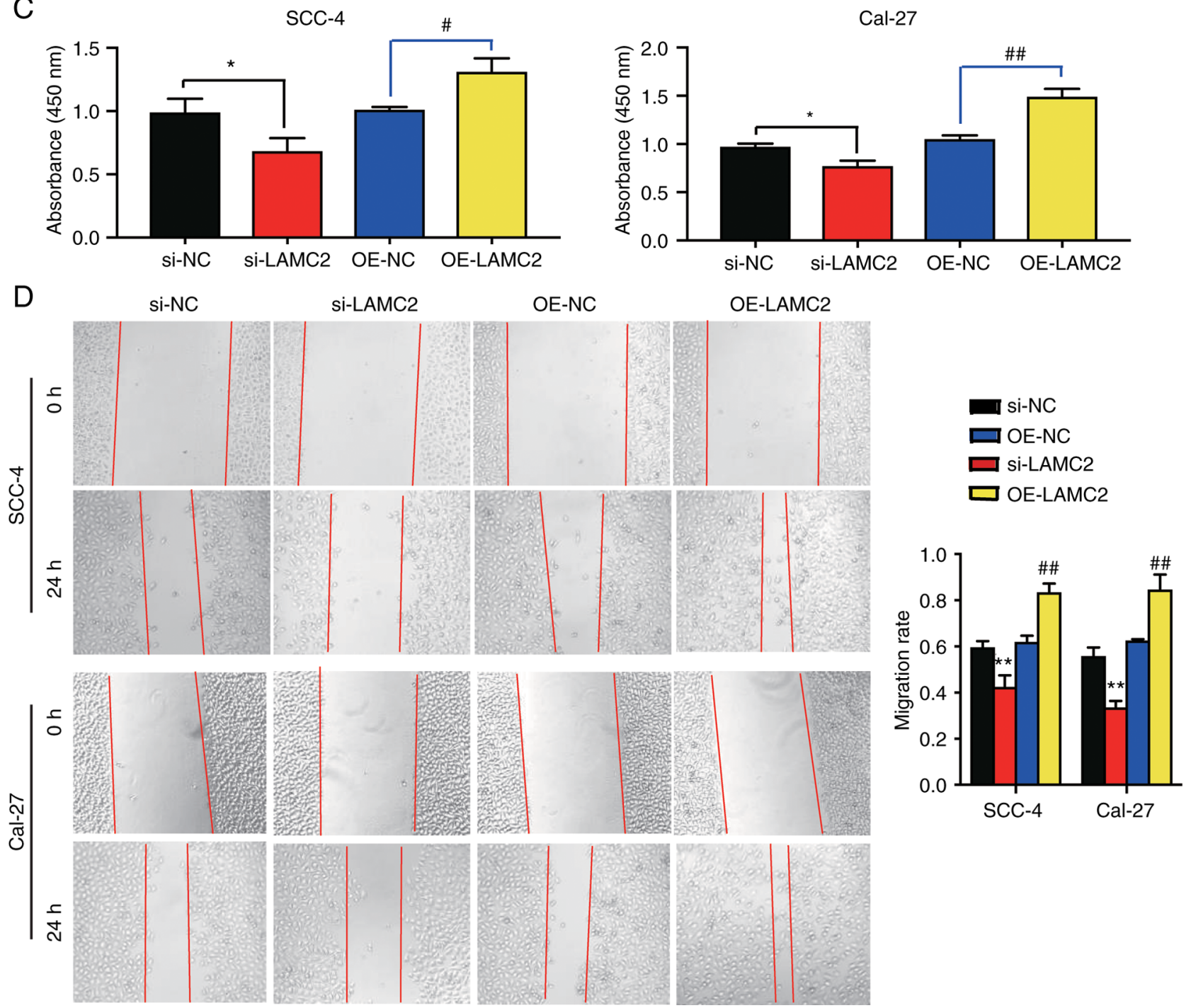

Figure 3. LAMC2 affects the viability, proliferation and migration of oral cancer cells. (A) Transfection efficiency in oral tumor cell lines following transfection with si-LAMC2, si-NC, OE-LAMC2 and OE-NC was detected by reverse transcription-quantitative PCR. ${ }^{* *} \mathrm{P}<0.01 \mathrm{vs}$. si-NC group; ${ }^{\# \#} \mathrm{P}<0.01 \mathrm{vs}$. OE-NC group. (B) Results of the Cell Counting Kit-8 assay in SCC-4 and Cal-27 cells transfected with si-LAMC2, si-NC, OE-LAMC2 and OE-NC. ${ }^{* *} \mathrm{P}<0.01$ vs. si-NC group; ${ }^{\# \#} \mathrm{P}<0.01$ vs. OE-NC group at $72 \mathrm{~h}$. (C) Results of the 5-bromo-2'-deoxyuridine incorporation assay in SCC-4 and Cal-27 cells transfected with si-LAMC2, si-NC, OE-LAMC2 and OE-NC. ${ }^{*} \mathrm{P}<0.05$ vs. si-NC group; ${ }^{*} \mathrm{P}<0.05$ and ${ }^{\# \#} \mathrm{P}<0.01$ vs. OE-NC group. (D) Wound healing assay results in $\mathrm{SCC}-4$ and Cal-27 cells. ${ }^{* *} \mathrm{P}<0.01$ vs. si-NC group; ${ }^{\# /} \mathrm{P}<0.01$ vs. OE-NC group. si-LAMC2, LAMC2 siRNA; si-NC, siRNA-negative control; OE-LAMC2, overexpression of LAMC2; OE-NC, negative control of overexpression; LAMC2, laminin subunit $\gamma 2$; si/siRNA, small interfering RNA.

LAMC2 with coordinated expression sustained the early-phase features of invading cancer cells in OSCC (35). Another study reported that LAMC2 expression was upregulated in OSCC tissues with $\alpha$-smooth muscle actin positivity, increasing to participate in the vascular basement membrane reorganization in tumor angioneogenesis (36). The results of the present study revealed that LAMC2 expression was upregulated in OC tissues and cell lines to promote cell viability, proliferation and migration.

Several miRNAs have been determined to function as tumor suppressors or promoters during OC genesis $(37,38)$. In 2016, the results of a microarray study demonstrated that 
A

Position 1230-1236 of LAMC2 3'UTR $5^{\prime}$...CUUUGCUCAACAGAACAUAUGUU

hsa-miR-5580-3p

3' CACGACCGAGUGAA--GUAUACAC

B

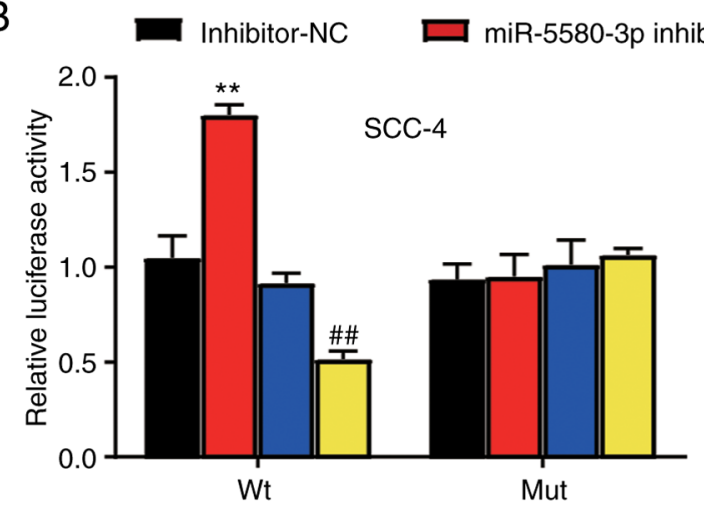

$\square$ Mimic-NC $\square$ miR-5580-3p mimic
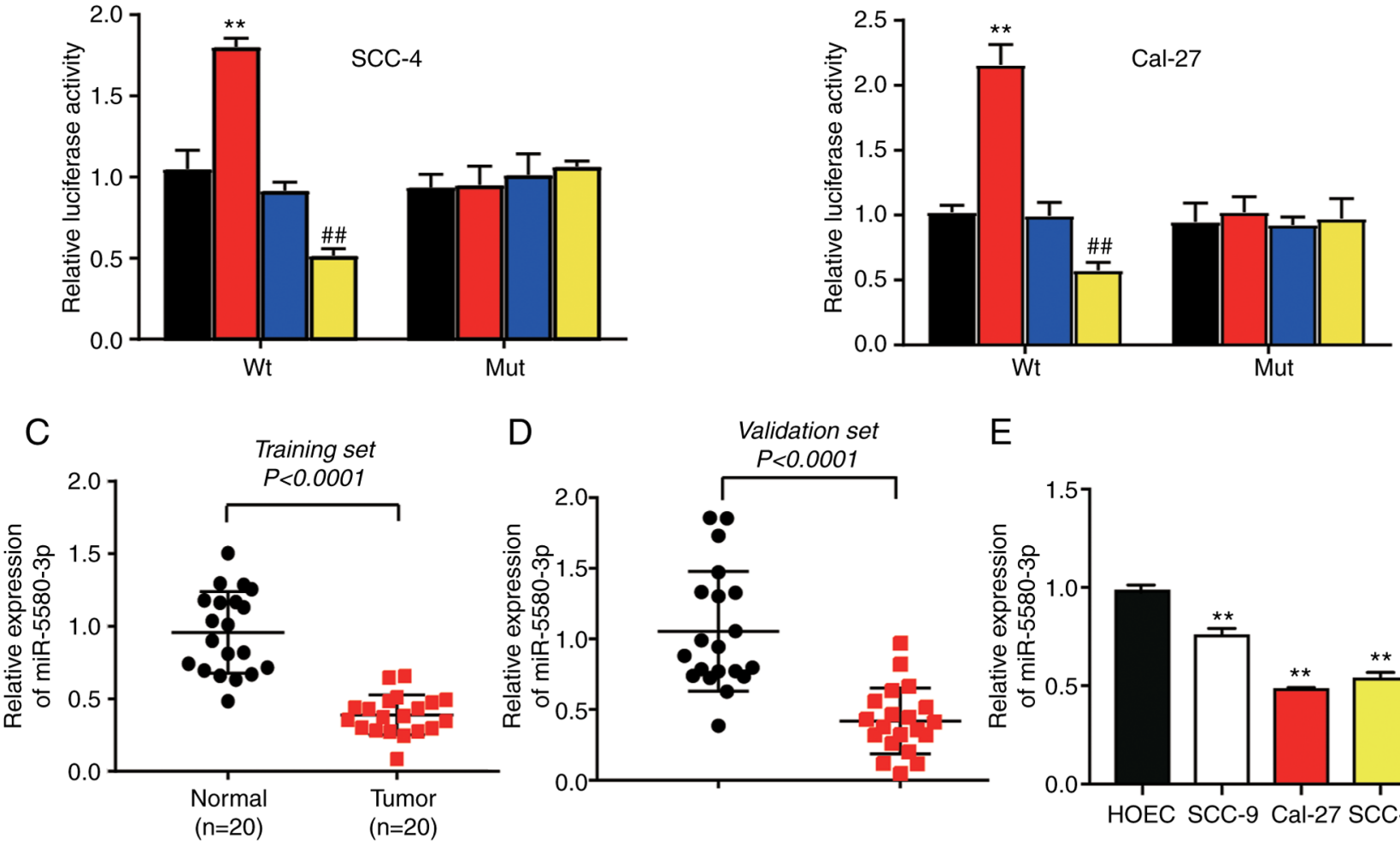

D Validation set

E
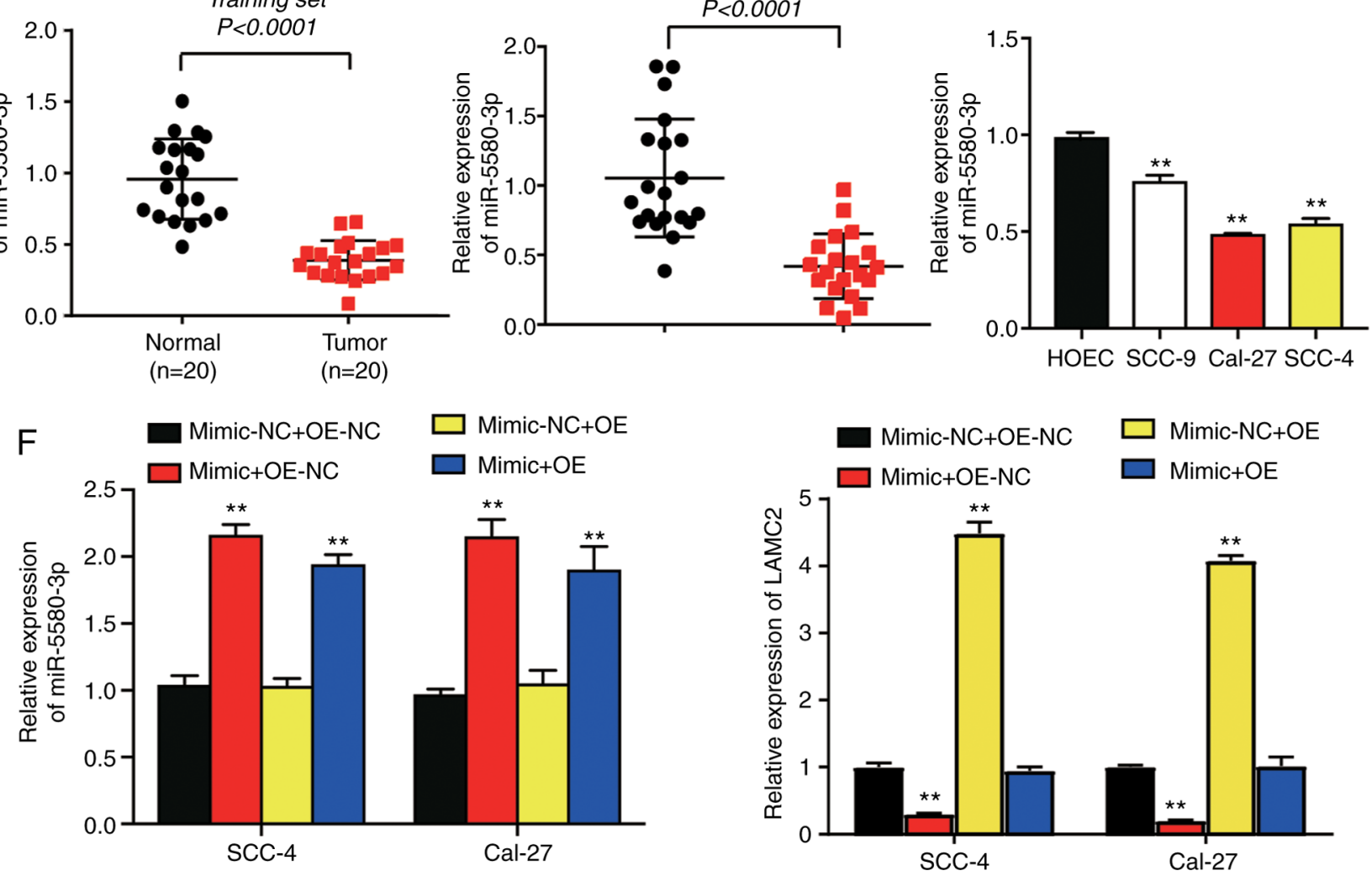

Figure 4. LAMC2 is a downstream target gene of miR-5580-3p. (A) Predicted binding sites of miR-5580-3p in the LAMC2 mRNA 3'-UTR according to TargetScan Human 7.2. (B) A luciferase reporter assay in SCC-4 and Cal-27 cells suggested that LAMC2 is a downstream target of miR-5580-3p. ${ }^{* *} \mathrm{P}<0.01$ vs. inhibitor-NC group; ${ }^{\# \#} \mathrm{P}<0.01$ vs. mimic-NC group. (C) miR-5580-3p expression was lower in oral tumor tissues than in healthy tissues in the training set. $\mathrm{P}<0.001$ (Wilcoxon test). (D) miR-5580-3p expression was lower in oral tumor tissues compared with that in healthy tissues in the validation set. $\mathrm{P}<0.001$ (Wilcoxon test). (E) miR-5580-3p expression was significantly lower in SCC-4 and Cal-27 cells than in HOEC cells. ${ }^{* *} \mathrm{P}<0.01$ vs. HOEC cell line. (F) Expression levels of miR-5580-3p and LAMC2 in co-transfection groups (miR-5580-3p mimic + OE-NC; mimic-NC + OE-NC; miR-5580-3p mimic + OE-LAMC2; mimic-NC+ OE-LAMC2) was detected by reverse transcription-quantitative PCR. ${ }^{* *} \mathrm{P}<0.01$ vs. mimic-NC + OE-NC group. Mimic-NC + OE-NC, miR-5580-3p mimic negative control + LAMC2 overexpression negative control; mimic + OE-NC, miR-5580-3p mimic + LAMC2 overexpression negative control; mimic-NC + OE, miR-5580-3p mimic negative control + LAMC2 overexpression; mimic + OE, miR-5580-3p mimic + LAMC2 overexpression; LAMC2, laminin subunit $\gamma 2$; miR-5580-3p, microRNA-5580-3p; Wt, wild-type; Mut, mutant; UTR, untranslated region; HOEC, human oral epithelial cell line.

let-7a, let-7d, let-7f and miR-16 were expressed at low levels in OSCC tissues, whereas the expression levels of miR-29b, miR-142-3p, miR-144, miR-203 and miR-223 were increased in OSCC tissues (37). However, one study demonstrated that miR-196 was associated with lymph node metastasis when highly overexpressed in OC tissues, thus resulting in enhanced cell migration and invasion (39). A study published in 2014 revealed that miR-99a, one of the most significantly 

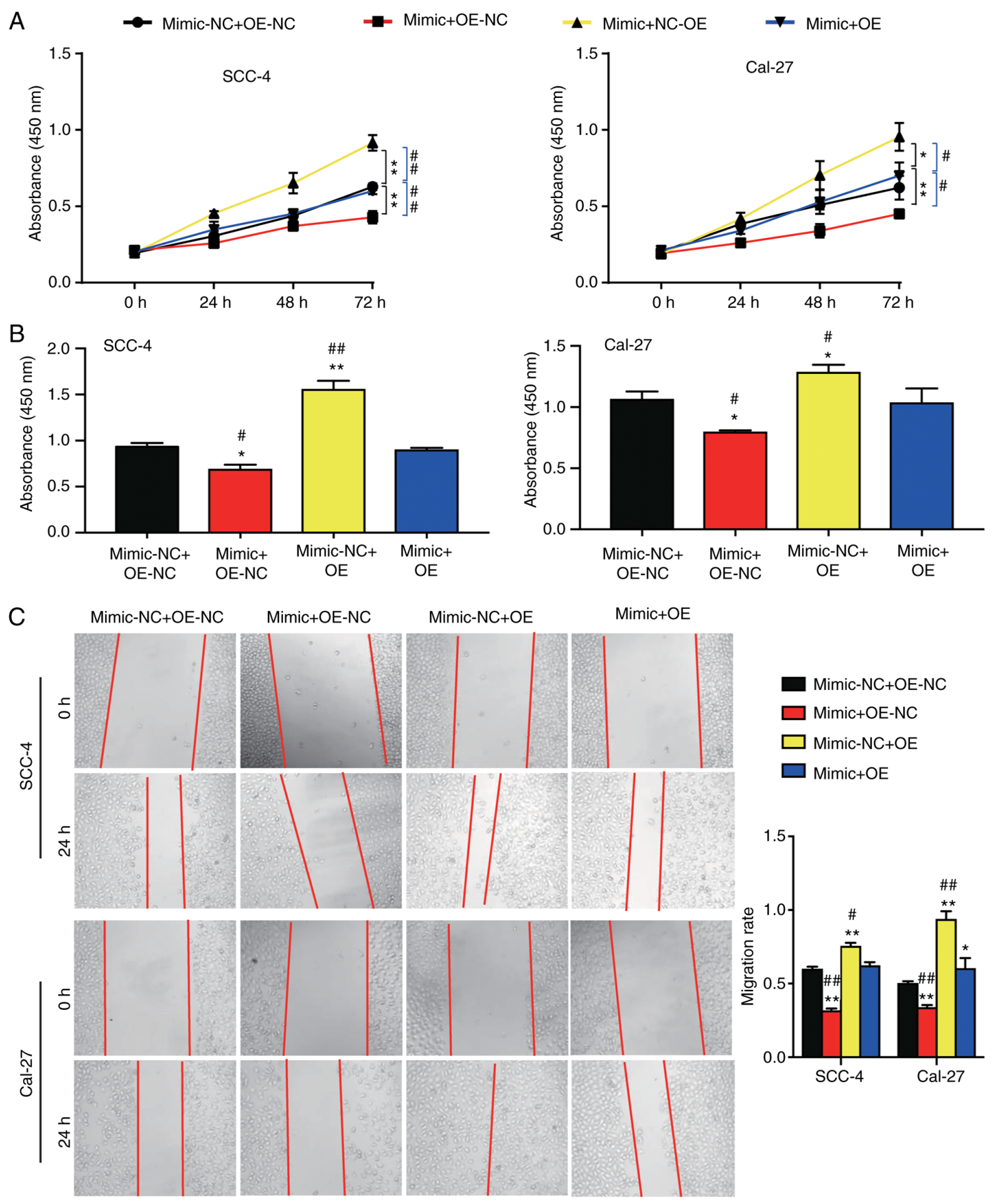

Figure 5. Effects of miR-5580-3p on cell viability, proliferation and wound healing via targeting of LAMC2. (A) Cell Counting Kit-8 assay results revealed that miR-5580-3p inhibited cell viability, while LAMC2 reversed its effect. (B) 5-bromo-2'-deoxyuridine incorporation assay results demonstrated that miR-5580-3p inhibited cell proliferation, while LAMC2 reversed its effect. (C) miR-5580-3p increased the wound healing rate, while LAMC2 reversed its effect. ${ }^{-P} \mathrm{P}<0.05$ and ${ }^{* *} \mathrm{P}<0.01$ vs. $\mathrm{NC}+\mathrm{OE}-\mathrm{NC}$ group; ${ }^{*} \mathrm{P}<0.05$ and ${ }^{\# \#} \mathrm{P}<0.01$ vs. mimic + OE group. Mimic-NC + OE-NC, miR-5580-3p mimic negative control + LAMC2 overexpression negative control; mimic + OE-NC, miR-5580-3p mimic + LAMC2 overexpression negative control; mimic-NC + OE, miR-5580-3p mimic negative control + LAMC2 overexpression; mimic + OE, miR-5580-3p mimic + LAMC2 overexpression; LAMC2, laminin subunit $\gamma 2$; miR-5580-3p, microRNA-5580-3p.

downregulated miRNAs in OSCC, decreased the migration and invasion of OSCC cells (40). In the present study, it was observed that miR-5580-3p expression was downregulated in both OC tissues and cell lines, and that it inhibited cell viability, proliferation and migration.
The present study provided additional insights into how miRNAs regulate OC. It has been widely hypothesized that a miRNA can bind to the 3'UTR of its target mRNA (41-43). For instance, miR-31-5p regulates the expression of extracellular PEG2 antagonistically, thereby enhancing prostaglandin E 
receptor 1-ERK-MMP9 (44). Furthermore, miR-125b, which is expressed at low levels in OSCC tissues, is a direct upstream gene of peroxiredoxin like $2 \mathrm{~A}$, and its overexpression in OSCC cells increases oxidative stress and inhibits the activity of OSCC cells (45). Additionally, LAMC2 has been reported to be targeted by other miRNAs and to affect OC cell phenotypes. For instance, LINC00511 is highly expressed in tongue squamous cell carcinoma, and it acts as a competing endogenous RNA sponging miR-765, finally upregulating LAMC2 expression to enhance cell proliferation and invasion (46). In HNSCC, LAMC2 is regulated by miR-29s to promote cell migration and invasion (47). In the present study, miR-5580-3p was demonstrated to be an upstream miRNA of LAMC2. By binding to the 3'UTR of LAMC2, miR-5580-3p decreased cell viability, proliferation and migration in OSCC.

Another study revealed that laminin-5 protein could co-deposit with large un-spliced tenascin-C in the extracellular matrix to promote invasion and metastasis in OSCC (48). Therefore, further experiments should be performed to study how LAMC2 enters the cell nucleus to remodel the extracellular matrix and thus influence tumor invasion. To further validate the current results, animal experiments could also be conducted in the future. Clinically, the log-rank test may not be applicable for survival plots where late stage crossover is present in LAMC2 prognostic analysis, so further verification should be performed using a weighted test, such as Renyi or Cramer-von Mises.

In summary, the present study demonstrated that miR-5580-3p suppressed cell viability, proliferation and migration by decreasing the expression levels of LAMC2. This means that, in the future, miR-5580-3p and LAMC2 may be used as potential biomarkers or even therapeutic targets for OC diagnosis and therapies.

\section{Acknowledgements}

Not applicable.

\section{Funding}

No funding was received.

\section{Availability of data and materials}

The datasets used and or/analyzed during the current study are available from the corresponding author on reasonable request.

\section{Authors' contributions}

BX and QL designed the study. RF performed most of the experiments. QL performed the data analysis and wrote the paper. BX and QL confirm the authenticity of all the raw data. All authors read and approved the final manuscript.

\section{Ethics approval and consent to participate}

The present study was approved by the Ethics Committee of Puai Hospital, Tongji Medical College, Huazhong University of Science and Technology (Wuhan, China; approval no. KY2020-501-01). All patients who participated in the present study provided written informed consent.

\section{Patient consent for publication}

Not applicable.

\section{Competing interests}

The authors declare that they have no competing interests.

\section{References}

1. Chen L, Zhang S, Wu J, Cui J, Zhong L, Zeng L and Ge S: circRNA_100290 plays a role in oral cancer by functioning as a sponge of the miR-29 family. Oncogene 36: 4551-4561, 2017.

2. Carnielli CM, Macedo CCS, De Rossi T, Granato DC, Rivera C, Domingues RR, Pauletti BA, Yokoo S, Heberle H, Busso-Lopes AF, et al: Combining discovery and targeted proteomics reveals a prognostic signature in oral cancer. Nat Commun 9: 3598, 2018.

3. Sophia J, Kowshik J, Dwivedi A, Bhutia SK, Manavathi B, Mishra R and Nagini S: Nimbolide, a neem limonoid inhibits cytoprotective autophagy to activate apoptosis via modulation of the PI3K/Akt/GSK-3 $\beta$ signalling pathway in oral cancer. Cell Death Dis 9: 1087, 2018.

4. Kang CJ, Lin CY, Yang LY, Ho TY, Lee LY, Fan KH, Wang HM, Huang SF, Chang KP, Fang KH, et al: Positive clinical impact of an additional PET/CT scan before adjuvant radiotherapy or concurrent chemoradiotherapy in patients with advanced oral cavity squamous cell carcinoma. J Nucl Med 56: 22-30, 2015.

5. Jardim JF, Francisco AL, Gondak R, Damascena A and Kowalski LP: Prognostic impact of perineural invasion and lymphovascular invasion in advanced stage oral squamous cell carcinoma. Int J Oral Maxillofac Surg 44: 23-28, 2015.

6. Hafiji J, Hussain W and Salmon P: Reconstruction of perioral defects post-Mohs micrographic surgery: A dermatological surgeon's approach. Br J Dermatol 172: 145-150, 2015.

7. Garg M, Kanojia D, Okamoto R, Jain S, Madan V, Chien W, Sampath A, Ding LW, Xuan M, Said JW, et al: Laminin-5gamma-2 (LAMC2) is highly expressed in anaplastic thyroid carcinoma and is associated with tumor progression, migration, and invasion by modulating signaling of EGFR. J Clin Endocrinol Metab 99: E62-E72, 2014.

8. Cotterill SJ: Chromosome 1. Cancer Genetics. http://www. cancer-genetics.org/clinkc01.htm. Accessed: April 12, 2021

9. Koshikawa N, Minegishi T, Nabeshima K and Seiki M: Development of a new tracking tool for the human monomeric laminin-gamma 2 chain in vitro and in vivo. Cancer Res 68: 530-536, 2008 .

10. Xu L, Hou Y, Tu G, Chen Y, Du YE, Zhang H, Wen S, Tang X, Yin J, Lang L, et al: Nuclear Drosha enhances cell invasion via an EGFR-ERK1/2-MMP7 signaling pathway induced by dysregulated miRNA-622/197 and their targets LAMC2 and CD82 in gastric cancer. Cell Death Dis 8: e2642, 2017.

11. Shou JZ, Hu N, Takikita M, Roth MJ, Johnson LL, Giffen C, Wang $\mathrm{QH}$, Wang $\mathrm{C}$, Wang $\mathrm{Y}$, Su $\mathrm{H}$, et al: Overexpression of CDC25B and LAMC2 mRNA and protein in esophageal squamous cell carcinomas and premalignant lesions in subjects from a high-risk population in China. Cancer Epidemiol Biomarkers Prev 17: 1424-1435, 2008.

12. Kosanam H, Prassas I, Chrystoja CC, Soleas I, Chan A, Dimitromanolakis A, Blasutig IM, Rückert F, Gruetzmann R, Pilarsky C, et al: Laminin, gamma 2 (LAMC2): A promising new putative pancreatic cancer biomarker identified by proteomic analysis of pancreatic adenocarcinoma tissues. Mol Cell Proteomics 12: 2820-2832, 2013.

13. Zhang Y, Zoltan M, Riquelme E, Xu H, Sahin I, Castro-Pando S, Montiel MF, Chang K, Jiang Z, Ling J, et al: Immune cell production of interleukin 17 induces stem cell features of pancreatic intraepithelial neoplasia cells. Gastroenterology 155: 210-223.e3, 2018.

14. Lin Y, Ge X, Zhang X, Wu Z, Liu K, Lin F, Dai C, Guo W and Li J: Protocadherin-8 promotes invasion and metastasis via laminin subunit $\gamma 2$ in gastric cancer. Cancer Sci 109: 732-740, 2018.

15. Li Z, Xu R and Li N: MicroRNAs from plants to animals, do they define a new messenger for communication? Nutr Metab (Lond) 15: 68, 2018. 
16. Reinhart BJ, Weinstein EG, Rhoades MW, Bartel B and Bartel DP: MicroRNAs in plants. Genes Dev 16: 1616-1626, 2002.

17. Bartel DP: MicroRNAs: Genomics, biogenesis, mechanism, and function. Cell 116: 281-297, 2004.

18. Xu X, Wang Y, Mojumdar K, Zhou Z, Jeong KJ, Mangala LS, Yu S, Tsang YH, Rodriguez-Aguayo C, Lu Y, et al: A-to-I-edited miRNA-379-5p inhibits cancer cell proliferation through CD97-induced apoptosis. J Clin Invest 129: 5343-5356, 2019.

19. Bhatia V, Yadav A, Tiwari R, Nigam S, Goel S, Carskadon S, Gupta N, Goel A,Palanisamy N and Ateeq B: Epigenetic silencing of miRNA-338-5p and miRNA-421 drives SPINK1-positive prostate cancer. Clin Cancer Res 25: 2755-2768, 2019.

20. Croset M, Pantano F, Kan CWS, Bonnelye E, Descotes F, Alix-Panabieres C, Lecellier CH, Bachelier R, Allioli N, Hong SS, et al: miRNA-30 family members inhibit breast cancer invasion, osteomimicry, and bone destruction by directly targeting multiple bone metastasis-associated genes. Cancer Res 78: 5259-2573, 2018.

21. Marcuello M, Duran-Sanchon S, Moreno L, Lozano JJ Bujanda L, Castells A and Gironella M: Analysis of A 6-mirna signature in serum from colorectal cancer screening participants as non-invasive biomarkers for advanced adenoma and colorectal cancer detection. Cancers (Basel) 11: 1542, 2019

22. Friedlander MR, Mackowiak SD, Li N, Chen W and Rajewsky N: miRDeep2 accurately identifies known and hundreds of novel microRNA genes in seven animal clades. Nucleic Acids Res 40 37-52, 2012.

23. Tuch BB, Laborde RR, Xu X, Gu J, Chung CB, Monighetti CK, Stanley SJ, Olsen KD, Kasperbauer JL, Moore EJ, et al: Tumor transcriptome sequencing reveals allelic expression imbalances associated with copy number alterations. PLoS One 5: e9317, 2010.

24. Bhosale PG, Cristea S, Ambatipudi S, Desai RS, Kumar R, Patil A, Kane S, Borges AM, Schäffer AA, Beerenwinkel N and Mahimkar MB: Chromosomal alterations and gene expression changes associated with the progression of leukoplakia to advanced gingivobuccal cancer. Transl Oncol 10: 396-409, 2017.

25. Agarwal V, Bell GW, Nam JW and Bartel DP: Predicting effective microRNA target sites in mammalian mRNAs. Elife 4 e05005, 2015.

26. Chamorro-Petronacci C, Perez-Sayáns M, Padín-Iruegas ME, Marichalar-Mendia X, Gallas-Torreira M and García García A: Differential expression of snoRNAs in oral squamous cell carcinomas: New potential diagnostic markers. J Enzyme Inhib Med Chem 33: 424-427, 2018.

27. Livak KJ and Schmittgen TD: Analysis of relative gene expression data using real-time quantitative PCR and the 2(-Delta Delta C(T)) method. Methods 25: 402-408, 2001

28. Soini Y, Maatta M, Salo S, Tryggvason K and Autio-Harmainen H: Expression of the laminin gamma 2 chain in pancreatic adenocarcinoma. J Pathol 180: 290-294, 1996.

29. Takahashi S, Hasebe T, Oda T, Sasaki S, Kinoshita T, Konishi M, Ochiai $\mathrm{T}$ and Ochiai A: Cytoplasmic expression of laminin gamma2 chain correlates with postoperative hepatic metastasis and poor prognosis in patients with pancreatic ductal adenocarcinoma. Cancer 94: 1894-901, 2002.

30. Koshikawa N, Moriyama K, Takamura H, Mizushima H, Nagashima Y, Yanoma S and Miyazaki K: Overexpression of laminin gamma 2 chain monomer in invading gastric carcinoma cells. Cancer Res 59: 5596-5601, 1999.

31. Hlubek F, Jung A, Kotzor N, Kirchner T and Brabletz T: Expression of the invasion factor laminin gamma2 in colorectal carcinomas is regulated by beta-catenin. Cancer Res 61: 8089-8093, 2001.

32. Kagesato Y, Mizushima H, Koshikawa N, Kitamura H, Hayashi H, Ogawa N, Tsukuda M and Miyazaki K: Sole expression of laminin gamma 2 chain in invading tumor cells and its association with stromal fibrosis in lung adenocarcinomas. Jpn J Cancer Res 92: 184-192, 2001.

33. Skyldberg B, Salo S, Eriksson E, Aspenblad U, Moberger B, Tryggvason K and Auer G: Laminin-5 as a marker of invasiveness in cervical lesions. J Natl Cancer Inst 91: 1882-1887, 1999.

34. Oku N, Sasabe E, Ueta E, Yamamoto T and Osaki T: Tight junction protein claudin-1 enhances the invasive activity of oral squamous cell carcinoma cells by promoting cleavage of laminin-5 gamma2 chain via matrix metalloproteinase (MMP)-2 and membrane-type MMP-1. Cancer Res 66: 5251-5257, 2006.
35. Lindberg P, Larsson A and Nielsen BS: Expression of plasminogen activator inhibitor-1, urokinase receptor and laminin gamma-2 chain is an early coordinated event in incipient oral squamous cell carcinoma. Int J Cancer 118: 2948-2956, 2006

36. Franz M, Wolheim A, Richter P, Umbreit C, Dahse R, Driemel O, Hyckel P, Virtanen I, Kosmehl H and Berndt A: Stromal laminin chain distribution in normal, hyperplastic and malignant oral mucosa: Relation to myofibroblast occurrence and vessel formation. J Oral Pathol Med 39: 290-298, 2010.

37. Manikandan M, Deva Magendhra Rao AK, Arunkumar G, Manickavasagam M, Rajkumar KS, Rajaraman R and Munirajan AK: Oral squamous cell carcinoma: microRNA expression profiling and integrative analyses for elucidation of tumourigenesis mechanism. Mol Cancer 15: 28, 2016.

38. Park NJ, Zhou H, Elashoff D, Henson BS, Kastratovic DA, Abemayor E, Abemayor E and Wong DT: Salivary microRNA: Discovery, characterization, and clinical utility for oral cancer detection. Clin Cancer Res 15: 5473-5477, 2009.

39. Lu YC, Chang JT, Liao CT, Kang CJ, Huang SF, Chen IH, Huang CC, Huang YC, Chen WH, Tsai CY, et al: OncomiR-196 promotes an invasive phenotype in oral cancer through the NME4-JNK-TIMP1-MMP signaling pathway. Mol Cancer 13: 218, 2014

40. Yen YC, Shiah SG, Chu HC, Hsu YM, Hsiao JR, Chang JY, Hung WC, Liao CT, Cheng AJ, Lu YC and Chen YW: Reciprocal regulation of microRNA-99a and insulin-like growth factor I receptor signaling in oral squamous cell carcinoma cells. Mol Cancer 13: 6, 2014

41. Wang H, Deng Q, Lv Z, Ling Y, Hou X, Chen Z, Dinglin X, Ma S, Li D, Wu Y, et al: N6-methyladenosine induced miR-143-3p promotes the brain metastasis of lung cancer via regulation of VASH1. Mol Cancer 18: 181, 2019.

42. Buonfiglioli A, Efe IE, Guneykaya D, Ivanov A, Huang Y, Orlowski E, Krüger C, Deisz RA, Markovic D, Flüh C, et al: let-7 MicroRNAs regulate microglial function and suppress glioma growth through toll-like receptor 7. Cell Rep 29: 3460-3471,e7, 2019.

43. Yu L, Wu D, Gao H, Balic JJ, Tsykin A, Han TS, Liu YD, Kennedy CL, Li JK, Mao JQ, et al: Clinical utility of a STAT3-regulated miRNA-200 family signature with prognostic potential in early gastric cancer. Clin Cancer Res 24: 1459-1472, 2018.

44. Lai YH, Liu H, Chiang WF, Chen TW, Chu LJ, Yu JS, Chen SJ, Chen HC and Tan BC: MiR-31-5p-ACOX1 axis enhances tumorigenic fitness in oral squamous cell carcinoma via the promigratory prostaglandin E2. Theranostics 8: 486-504, 2018.

45. Chen YF, Wei YY, Yang CC, Liu CJ, Yeh LY, Chou CH, Chang KW and Lin SC: miR-125b suppresses oral oncogenicity by targeting the anti-oxidative gene PRXL2A. Redox Biol 22: 101140, 2019 .

46. Ding J, Yang C and Yang S: LINC00511 interacts with miR-765 and modulates tongue squamous cell carcinoma progression by targeting LAMC2. J Oral Pathol Med 47: 468-476, 2018.

47. Kinoshita T, Nohata N, Hanazawa T, Kikkawa N, Yamamoto N, Yoshino H, Itesako T, Enokida H, Nakagawa M, Okamoto Y and Seki N: Tumour-suppressive microRNA-29s inhibit cancer cell migration and invasion by targeting laminin-integrin signalling in head and neck squamous cell carcinoma. Br J Cancer 109: 2636-2645, 2013.

48. Franz M, Hansen T, Richter P, Borsi L, Bohmer FD, Hyckel P, Schleier P, Katenkamp D, Zardi L, Kosmehl H and Berndt A: Complex formation of the laminin-5 gamma2 chain and large unspliced tenascin- $\mathrm{C}$ in oral squamous cell carcinoma in vitro and in situ: Implications for sequential modulation of extracellular matrix in the invasive tumor front. Histochem Cell Biol 126 125-131, 2006.

This work is licensed under a Creative Commons Attribution-NonCommercial-NoDerivatives 4.0 International (CC BY-NC-ND 4.0) License. 